\title{
Investigating the influence of online interpersonal interaction on purchase intention based on stimulus-organism-reaction model
}

\author{
Yaqin $\mathrm{Liu}^{1,2^{*}}$, Xinxing Luo ${ }^{1}$ and $\mathrm{Yi} \mathrm{CaO}^{2,3^{*}}$
}

*Correspondence:
yaqinliu@csu.edu.cn;
$812825114 @ q q . c o m$
${ }^{1}$ Business School, Central
South University, Changsha,
China
${ }^{2}$ School of Mathematics
and Statistics, Hunan Normal
University, Changsha, China
Full list of author information
is available at the end of the
article

*Correspondence:

1 Business School, Central South University, Changsha, China

School of Mathematics article

\begin{abstract}
Based on the stimulus-organism-reaction model, we study the direct effects of the three interpersonal attraction factors (perceived similarity, perceived familiarity, and perceived expertise) on purchase intention in the social commerce era, as well as the mediating roles of the normative and informational influence of reference groups in the above relationship. We apply structural equation model to the study samples consisting of 490 WeChat users. The results of empirical research indicate that the three interpersonal attraction factors have positive effects on purchase intention. Both the normative and informational influence fully mediate the effect of perceived familiarity on purchase intention, but only partially mediate the effects of perceived similarity and perceived expertise on purchase intention. The findings provided practitioners with insights into enhancing users' intention to purchase in social commerce.
\end{abstract}

Keywords: Online interpersonal interaction, Reference group, Purchase intention, SOR model

\section{Background}

On January 31, 2018, the China Internet Network Information Center (CNNIC) released the 41st Statistical Report on China's Internet Development in Beijing. By December 2017, the number of Internet users in China reached 772 million, accounting for 55.8\% of the total population, which exceeds the global average (51.7\%) by $4.1 \%$ and the Asian average $(46.7 \%)$ by $9.1 \%$. The rapid development of digital technology and Internet has changed the traditional model of interpersonal interaction. The "Hyperpersonal Communication" model states that people who are engaged in computer-mediated communication may experience greater levels of intimacy, unity and liking than face-to-face interaction users [1]. Online interpersonal interaction demonstrates the relationships of social groups on Internet platforms. It is a practical activity that shares knowledge through digitized and symbolized information among the highly integrated societies and individuals online and in the real world.

WeChat is the most popular and widely used social platform app in China. Based on an analysis of WeChat user data, the WeChat Users E Business Ecosystem Report 2017 showed that by December 2016, there were about 889 million active WeChat users every month, and those users spent 1967 min on average on WeChat each month. About 45\%

(c) The Author(s) 2018. This article is distributed under the terms of the Creative Commons Attribution 4.0 International License (http://creativecommons.org/licenses/by/4.0/), which permits unrestricted use, distribution, and reproduction in any medium, provided you give appropriate credit to the original author(s) and the source, provide a link to the Creative Commons license, and indicate if changes were made. 
of them have more than 200 contacts, and most users add more than 5 WeChat friends every month. The information consumption promoted by WeChat has reached 1742.5 billion RMB annually. As a popular social tool, WeChat is gradually changing the social method of the interaction. The overall relationship has been transformed from a strong relationship with high similarity, high intimacy, and high reciprocity to a weak relationship with strong differences and low popularity. Therefore, the web 2.0 era social networking platforms, for instance, WeChat, have gradually become the main tools for people to express their emotions or share their experiences.

However, self-cognition and behaviors of an individual are readily influenced by emotions and attitudes of others. Hence, the process of interpersonal interaction could form different reference groups. When people consider whether or not to purchase a product, they will evaluate it according to the attitude and value orientations of their reference groups [2]. They will refer to their families and friends, even the people who are never met before. With the rapid development of the "Internet+", the online interpersonal interactions and reference groups have become important influence factors for consumers' purchase intention. Although many scholars have conducted extensive research on interpersonal interactions, reference groups and consumers' purchase intention, they only focused on the on-site service and traditional face-to-face interactions, and there is no conclusive results regarding the influence mechanism of online interpersonal interaction on purchase intention.

Previous studies have shown that the structural equation model based on bootstrap can overcome the shortcoming of Sobel test method in dealing with small sample, and can effectively reduce measuring error. Hayes and Scharkow [3] examines whether the method makes a difference in the conclusion of an investigator, and finds that the bias corrected bootstrap confidence interval is the most trustworthy test if power is of utmost concern.

The purpose of this paper is to explore the influence of the interpersonal interaction factors on purchase intention from the perspective of the online reference groups. The novelty of the research is the identification of the significant factors that affects the purchase intention, and the application of structural equation modeling analysis based on bootstrap to study. This study bridged the research gaps in the social commerce literature. By using the theory of SOR, we propose a research model via WeChat data. In addition, we found the influence mechanism of interpersonal interactions on purchase intention.

\section{Literature review and research hypothesis The SOR model}

The concept of SOR model was originally developed from stimulus response theory. This model describes how individuals respond to external stimuli. Later, the SOR model was improved by incorporating the concept of organism between stimulus and respond by Mehrabian and Russell [4]; the SOR model treats environmental cues as act as stimuli that affect an individual's cognitive and affective reactions, which can affect individual's internal cognitions and emotions, in turn, affect behavior. In social commerce context, stimulus factors include content, network and interaction characteristics. Organism refers to the individual's internal cognitions and emotions state, such as value 
perception, social/relational oriented perception and affection. And response includes factors like search, evaluation and purchase, etc.

There are two reasons for the application of the SOR paradigm as a holistic theory. First, many studies applied the SOR model to explore consumers' behavior in online environments. For example, using the SOR framework, Park et al. [5] examined the effects of online social network structure characteristics on network involvement and purchase intention. Liu et al. [6] adopted the SOR model to understand the impact of interpersonal interaction factors and flow experience on purchase intention. Second, the SOR model provides a structural manner to explore the impact of interpersonal interaction factors and customer experiences on purchase intention.

\section{Interpersonal interaction factors as environmental stimuli (S)}

Recent research identified three aspects of interpersonal interactions: (1) the first is the theoretical characteristic of spreading interpersonal relationships. Interpersonal communication is the process of self-disclosure, self-presentation, and self-cognition. The three-dimensional theory of interpersonal relationships states that people want to satisfy the need for affection through emotional communication, satisfy the need for inclusion through the exchange of information, and satisfy the need for control through cognitive communication [7]. (2) The second is the characteristic of interpersonal interaction and the psychological needs in the virtual community. The open and inclusive Internet expands the space for interpersonal communication and enhanced the universality and autonomy of human interaction [8]. However, the anonymity of online social interactions has resulted in a lack of trust in interpersonal communication and has alienated emotions. (3) The third is the application of interpersonal communication in marketing. Customer interaction significantly influences product marketing. Bruhn [9] demonstrated that the quality of customer interaction in B2B virtual brand communities has a positive effect on brand loyalty. Customers will consider the reviews of others as an important information source [7]. Positive information obtained through human interaction leads to a greater willingness to purchase a product $[10,11]$.

\section{Influence of reference group as customer internal states (0)}

Hyman [12] believed that people realize their social status by comparing themselves to reference groups and that recognition and judgment are two different attitudes within reference groups. After Hyman's study, the research on reference groups has evolved to many different areas such as education, marketing, and economics and has quickly expanded from real world groups to virtual individuals or groups. Park and Lessig [2] defined reference groups as actual or imaginary individuals or groups that influence the standards for individual evaluations, aspirations, and behaviors. When studying consumer behavior from the perspective of reference groups, Deutsch and Gerard [13] found that the influence mechanism of the reference group on consumer behavior could be divided into informational and normative influence. The former is the reference basis for consumers seeking information from the group and occurs as the result of critical thinking, while the latter refers to the influence of the group members' expectations on consumers' consumption behaviors and occurs as the result of peripheral thinking rather than central routing [14]. 
Reference group theory has been widely applied in online marketing, especially with the current continuous development of the Internet.

\section{Purchase intention as response ( $R$ )}

In the social commerce context, a customer is exposed to various interpersonal interaction factors and influence, such as perceived similarity, perceived familiarity, perceived expertise, informational influence and normative influence, which will stimulate consumers to purchase [15]. Further, we found that many studies adopted the SOR model to understand consumers' social commerce intention and purchase intention in social commerce [6]. Therefore, we use purchase intention as response in our research.

\section{Interpersonal interaction factors $(\mathrm{S})$ and influence of reference group (O)}

In social commerce, customers tend to interact more with familiar members [15]. They obtain or exchange information more frequently with familiar friends and are influenced easily [16]. Recent research indicates that familiarity with group members contributes to group norms [17]. Group members tend to be influenced more by the norms and values of familiar members than by unfamiliar ones. Therefore, the following hypotheses are proposed:

H1a Perceived familiarity is positively related to the informational influence.

H1b Perceived familiarity is positively related to the normative influence.

Similarity-attraction theory shows individuals are attracted by those who are similar to them [18]. Therefore, individuals tend to exchange information with those who have similar values, beliefs or norms [15]. Perceived similarity contributes to the development of close relationships, and will lead to greater levels of social affiliation [19]. From this perspective, individuals tend to be more influenced by the norms and values of similar ones. So, it posits that

$\mathrm{H} 2 \mathrm{a}$ Perceived similarity is positively related to the informational influence.

$\mathrm{H} 2 \mathrm{~b}$ Perceived similarity is positively related to the normative influence.

The perceived expertise is also predicted to have a positive effect on informational and normative influence. People seek information from individuals with perceived expertise to reduce risks [20]. Consumer expertise affects the knowledge for a product for choice [21]. The theory of social comparison postulates that people attempt to make a better choice with the help of the others that are better than themselves [22]. Therefore, it is expected that

H3a Perceived expertise is positively related to the informational influence.

$\mathrm{H} 3 \mathrm{~b}$ Perceived expertise is positively related to the normative influence. 


\section{Influence of reference group ( 0 ) and purchase intention (R)}

Most researches concentrate on the influence mechanism of reference groups on consumer behavior. The influence research of reference groups also identifies two forms of peer influence: normative and informational.

Normative influence is defined as "the tendency to conform to the expectations of others" [23], and has been shown to be positively associated with consumer behaviors of online shopping [24]. Informational influence can be viewed as the pressure to accept information obtained from others as evidence of reality [13]. Accordingly, people who try to find the best choice will make efforts to obtain more information from others. Kuan et al. [25] confirmed that informational influence is as a determining factor of purchase decisions in the online environment. In addition, they find that both informational social influence and normative social influence affect consumers' purchasing decisions in group buying sites [25].

In summary, this paper focuses on the impact of online reference groups on consumers' purchase intention from the aspects of informational and normative influence. Thus, we state the following hypotheses:

H4 Informational influence has a positive effect on consumers' purchase intention. H5 Normative impact has a positive effect on consumers' purchase intention.

\section{Interpersonal interaction factors (S) and purchase intention (R)}

According to the three-dimension theory of interpersonal relation, emotional communication is an important part of group interaction. Groups with matched personality traits are more likely to produce positive and efficient interactions [26, 27]. The interaction behavior between groups will stimulate positive emotions. Therefore, the emotional resonance (i.e., perceived similarity) generated by consumer interactions can positively stimulate purchase intention. The uncertainty of consumer information exchange is relatively high, since it is affected by certain features of the Internet, which makes consumer trust complex and diverse [28]. Frequent intimate and familiar interactions among parties are believed to create stronger mutual trust among consumers. Therefore, strong human interactions (i.e., perceived familiarity) have a positive effect on the consumption behaviors of a group. In addition, as a result of studying information processing and perception communication of group interpersonal interaction, it is found that the expertise displayed by information interaction participants had an effect on the group's purchase intention [29,30]. The perceived expertise of community members in the context of social commerce had a positive effect on purchase intention by influencing the perceived value of the customer [31].

However,the dimensions of interpersonal communication are not clearly defined. This paper combines the theory and psychological characteristics of interpersonal communication to explore the influence of interpersonal interaction on consumers' purchase intention from the aspects of perceived similarity, perceived familiarity, and perceived expertise. 
H6 Perceived similarity has a positive effect on consumers' purchase intention.

H7 Perceived familiarity has a positive effect on consumers' purchase intention.

H8 Perceived expertise has a positive effect on consumers' purchase intention.

On the Internet, interpersonal interaction stimulates the informational and normative influence of the reference group, reinforces the consumers' convergence into the reference group in behavioral decision-making, and promotes the consumer's purchase intention. On the basis of the aforementioned arguments, we hypothesize the following:

H9 Informational influence mediates the relationship between interpersonal interaction factors and purchase intention.

H10 Normative influence mediates the relationship between interpersonal interaction factors and purchase intention.

Based on the above theoretical analysis, the proposed research model and ten hypotheses are showed in Fig. 1.

\section{Research methodology}

\section{Questionnaire design}

Questionnaires are devised for collecting responder's psychological responses while occurring to such situation [6]. The measures for normative and informative influences construct adapted from Bearden et al. [32] and Shen et al. [15]. Purchase intention was measured using items adapted from Bai [33]. A revised questionnaire was created after interviewing WeChat users in different social strata, age groups, and genders, taking advices from experts and scholars, and analyzing the content validity of the items. The final questionnaire was formed after small-scale pre-testing that required some items to be deleted and some items to be screened.

The questionnaire used the Likert scales. The responses for the questionnaire items, namely, Strongly Agree, Agree, Neutral, Disagree, and Strongly Disagree are coded as " 5 , 4, 3, 2, 1". Measurement scale items are shown in Table 1.

\section{Data collection}

The sample data were mainly derived from college students, with a total of 533 questionnaires issued. After deleting the surveys with invalid or missing data, 490 valid

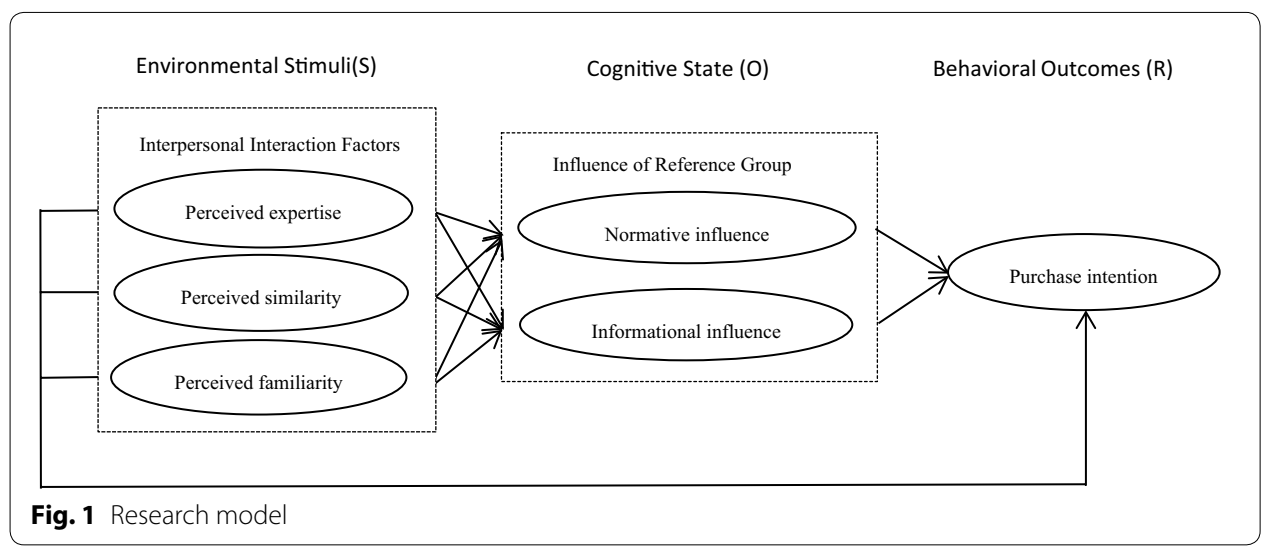


Table 1 Scale design

\begin{tabular}{|c|c|c|c|}
\hline Construct & Code & Measures & Sources \\
\hline \multirow[t]{4}{*}{ Perceived expertise } & A10_1 & $\begin{array}{l}\text { Some users in WeChat's Moments are very } \\
\text { knowledgeable about many brands or prod- } \\
\text { ucts }\end{array}$ & \multirow[t]{4}{*}{ Liu et al. [6] } \\
\hline & A10_2 & $\begin{array}{l}\text { Some users in WeChat's Moments are experts on } \\
\text { many brands or products }\end{array}$ & \\
\hline & A10_3 & $\begin{array}{l}\text { Some users in WeChat's Moments are highly } \\
\text { experienced in consuming the products }\end{array}$ & \\
\hline & A10_4 & $\begin{array}{l}\text { Compared to other similar social media, WeChat } \\
\text { has a lot of information and knowledge about } \\
\text { brands or products }\end{array}$ & \\
\hline \multirow[t]{4}{*}{ Perceived similarity } & A11_1 & $\begin{array}{l}\text { With regard to the styles in brands or products, I } \\
\text { am similar to some users in WeChat's Moments }\end{array}$ & \multirow[t]{4}{*}{ Liu et al. [6] } \\
\hline & A11_2 & $\begin{array}{l}\text { With regard to the tastes in brands or products, I } \\
\text { am similar to some users in WeChat's Moments }\end{array}$ & \\
\hline & A11_3 & $\begin{array}{l}\text { With regard to my likes and dislikes about brands } \\
\text { or products, I am similar to users in WeChat's } \\
\text { Moments }\end{array}$ & \\
\hline & A11_4 & $\begin{array}{l}\text { With regard to preferences in brands or prod- } \\
\text { ucts, I lam similar to users in WeChat's Moments }\end{array}$ & \\
\hline \multirow[t]{4}{*}{ Perceived familiarity } & A12_1 & $\begin{array}{l}\text { Users in WeChat's Moments are as familiar to me } \\
\text { as good friends }\end{array}$ & \multirow[t]{4}{*}{ Liu et al. [6] } \\
\hline & A12_2 & $\begin{array}{l}\text { I maintain close contacts with users on the } \\
\text { WeChat Moments }\end{array}$ & \\
\hline & A12_3 & $\begin{array}{l}\text { I have frequent interactions with other users on } \\
\text { the WeChat Moments through commenting or } \\
\text { replying behaviors }\end{array}$ & \\
\hline & A12_4 & $\begin{array}{l}\text { I often communicate with users in the WeChat } \\
\text { Moments }\end{array}$ & \\
\hline \multirow[t]{4}{*}{ Informational influence } & A13_1 & $\begin{array}{l}\text { If I have little experience with a product, I usually } \\
\text { ask usersin the WeChat Moments about the } \\
\text { product }\end{array}$ & \multirow[t]{4}{*}{$\begin{array}{l}\text { Bearden et al. [32]; Shen et } \\
\text { al. [15] }\end{array}$} \\
\hline & A13_2 & $\begin{array}{l}\text { I often consult other users on the WeChat } \\
\text { Moments to help choose the best products }\end{array}$ & \\
\hline & A13_3 & $\begin{array}{l}\text { In order to purchase the right product, I usu- } \\
\text { ally observe what other usersof the WeChat } \\
\text { Moments are buying and using }\end{array}$ & \\
\hline & A13_4 & $\begin{array}{l}\text { I often collect information from users in the } \\
\text { WeChat Moments about a product before I } \\
\text { buy it }\end{array}$ & \\
\hline \multirow[t]{3}{*}{ Normative influence } & A14_1 & $\begin{array}{l}\text { It is very important to me whether the users in } \\
\text { the WeChat Moments like the products and } \\
\text { brands I buy }\end{array}$ & \multirow[t]{3}{*}{$\begin{array}{l}\text { Bearden et al. [32]; Shen et } \\
\text { al. [15] }\end{array}$} \\
\hline & A14_3 & $\begin{array}{l}\text { I achieve a sense of belonging by purchasing the } \\
\text { same products or brands that other users of } \\
\text { the WeChat Moments purchase }\end{array}$ & \\
\hline & A14_4 & $\begin{array}{l}\text { I hope that my friends on the WeChat Moments } \\
\text { will like the products I purchase online }\end{array}$ & \\
\hline \multirow[t]{3}{*}{ Purchase intention } & A15_1 & $\begin{array}{l}\text { I obtained product information from the WeChat } \\
\text { Moments and have purchased the product }\end{array}$ & \multirow[t]{3}{*}{ Bai et al. [33] } \\
\hline & A15_2 & $\begin{array}{l}\text { I obtained product information from the WeChat } \\
\text { Moments and immediately purchased the } \\
\text { product }\end{array}$ & \\
\hline & A15_3 & $\begin{array}{l}\text { I obtained product information from WeChat } \\
\text { Moment and might purchase the product in } \\
\text { the future }\end{array}$ & \\
\hline
\end{tabular}


questionnaires were obtained. The demographic characteristics of respondents were as follows: women accounted for $65.8 \%$, and men accounted for $34 \%$; respondents with undergraduate or higher education that were 19 to 24 years old accounted for $94 \%$ and $85 \%$, respectively; $60 \%$ of the respondents used WeChat more than $1 \mathrm{~h}$ per day; $50 \%$ of the respondents spent more than $100 \mathrm{RMB}$ per month on WeChat shopping; and approximately $56 \%$ of the respondents used WeChat for more than 2 years. The statistics indicated that the respondents had used WeChat for a relatively long time and had rich online shopping experiences. The sample is a representative of the population shopping on the WeChat app.

\section{Data analysis and discussion}

\section{Scale reliability and validity test}

Cronbach's $\alpha$ values were used to test the reliability of the scale. The value of Cronbach's $\alpha$ in each scale is above 0.9 , indicating that the scale items are consistent and that the scale has high reliability. The test results are tabulated in Table 2.

In terms of content validity, after integrating the existing literature, expert validations and pre-test analyses, each scale item reflects the target content representatively. Therefore, the content validity of the scale is considered to be relatively high. In terms of the construct validity, all the items were used to conduct an exploratory factor analysis and demonstrate the structural logic of the scale. The KMO (Kaiser-Meyer-Olkin) value is 0.973. The MSA (Measure of Sample Adequacy) values of the items are all above 0.953, which proves that the scale is suitable for factor analysis. The analysis results are tabulated in Table 3.

After the exploratory factor analysis, six common factors were extracted, of which factor one includes items A12-1 to A12-4 (perceived familiarity), factor two includes A11-1 to A11-4 (perceived similarity), factor three includes A10-1 to A10-4 (perceived expertise), factor four includes A13-1 to A13-4 (informative influence), factor five includes A14-1, A14-3, and A14-4 (normative influence), and factor six includes A15-1 to A15-3 (purchase intention). The results are consistent with the theoretical structure of the scale.

\section{Model fitting analysis}

Analysis of moment structures (AMOS) software was applied for the confirmatory factor analysis of the overall model structure. The results of fitting are shown in Fig. 2, in which the values are all normalized estimates. We also used goodness-of-fit to assess the

Table 2 Scale reliability analysis

\begin{tabular}{ll}
\hline Construct & Cronbach's a \\
\hline Perceived expertise & 0.943 \\
Perceived similarity & 0.967 \\
Perceived familiarity & 0.917 \\
Informational influence & 0.946 \\
Normative influence & 0.932 \\
Purchase intention & 0.913 \\
\hline
\end{tabular}


Table 3 Exploratory factor analysis results

\begin{tabular}{lllllll}
\hline Code & Component & \multicolumn{1}{l}{} \\
\cline { 2 - 6 } & $\mathbf{1}$ & $\mathbf{2}$ & $\mathbf{3}$ & $\mathbf{4}$ & $\mathbf{5}$ & $\mathbf{6}$ \\
\hline A12_4 & .813 & .223 & .216 & .214 & .159 & .190 \\
A12_2 & .799 & .205 & .233 & .216 & .179 & .117 \\
A12_3 & .781 & .199 & .185 & .209 & .186 & .261 \\
A12_1 & .661 & .303 & .317 & .184 & .242 & .095 \\
A11_3 & .301 & .746 & .327 & .275 & .199 & .240 \\
A11_4 & .311 & .730 & .354 & .280 & .195 & .218 \\
A11_2 & .279 & .728 & .329 & .293 & .217 & .236 \\
A11_1 & .278 & .723 & .322 & .234 & .277 & .231 \\
A10_1 & .271 & .277 & .751 & .240 & .198 & .252 \\
A10_2 & .302 & .325 & .729 & .258 & .229 & .192 \\
A10_3 & .291 & .314 & .723 & .296 & .146 & .205 \\
A10_4 & .271 & .368 & .661 & .267 & .237 & .195 \\
A13_4 & .280 & .288 & .285 & .707 & .273 & .204 \\
A13_2 & .267 & .308 & .287 & .705 & .223 & .238 \\
A13_3 & .267 & .306 & .272 & .651 & .322 & .275 \\
A13_1 & .305 & .214 & .329 & .617 & .284 & .279 \\
A14_1 & .317 & .249 & .263 & .309 & .708 & .202 \\
A14_3 & .290 & .290 & .236 & .373 & .654 & .295 \\
A14_4 & .303 & .290 & .256 & .349 & .638 & .347 \\
A15_1 & .280 & .274 & .261 & .304 & .256 & .723 \\
A15_3 & .218 & .333 & .289 & .340 & .287 & .606 \\
A15_2 & .306 & .328 & .350 & .298 & .294 & .588 \\
\hline & & & & & & \\
\hline
\end{tabular}

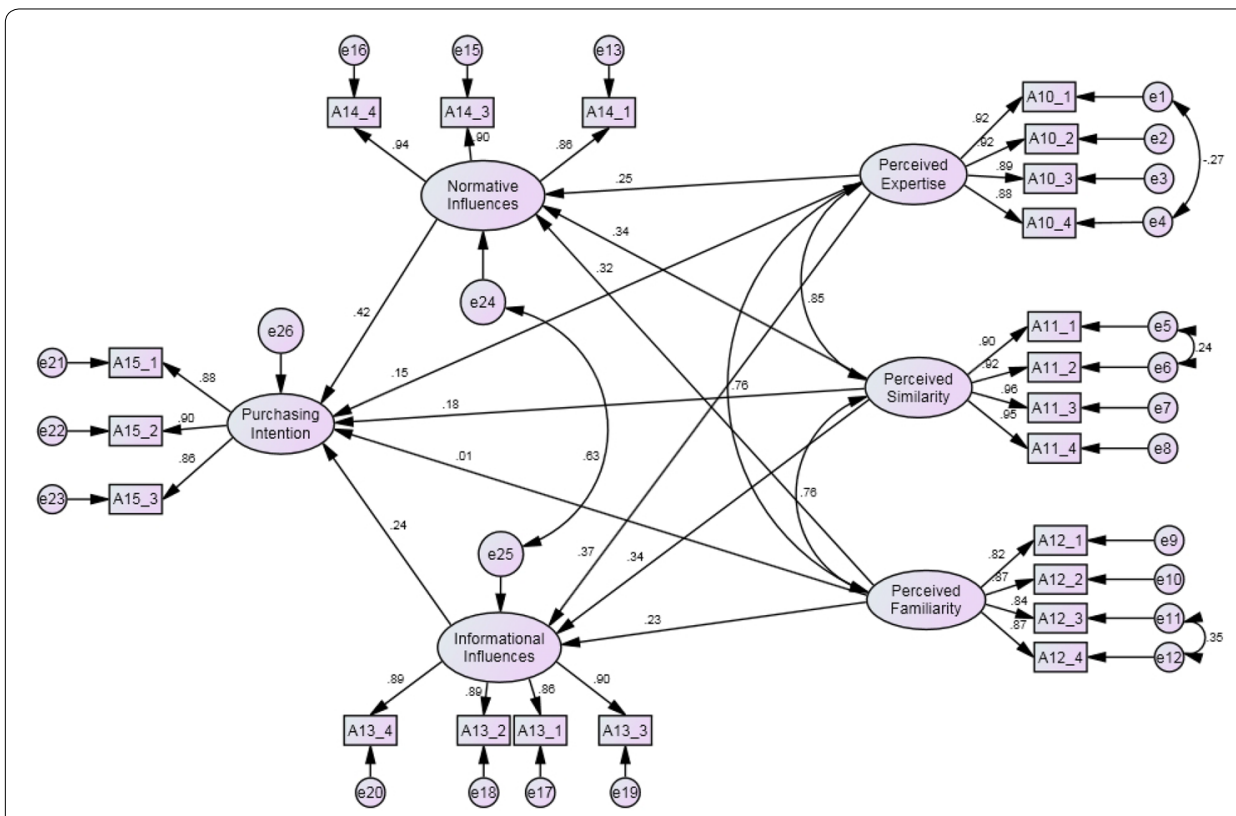

Fig. 2 Structural equation model and path analysis results 
Table 4 Overall structure fitting analysis of the model

\begin{tabular}{llll}
\hline Fitting Indicator & Ideal range & Indicator value & Fitting result \\
\hline Chi square /degree of freedom (CMIN/DF) & $1-3$ & 1.952 & Excellent \\
Root mean residual (RMR) & $<0.05$ & 0.034 & Excellent \\
Goodness of fit index (GFI) & $>0.9$ & 0.938 & Excellent \\
Adjusted goodness of fit index (AGFI) & $>0.9$ & 0.918 & Excellent \\
Parsimony goodness of fit index (PGFI) & $>0.5$ & 0.712 & Excellent \\
Normed fit index (NFI) & $>0.9$ & 0.973 & Excellent \\
Relative fit index (RFI) & $>0.9$ & 0.968 & Excellent \\
Incremental fit index (IFI) & $>0.9$ & 0.987 & Excellent \\
Tucker Lewis Index (TLI) & $>0.9$ & 0.984 & Excellent \\
Comparative fit index (CFI) & $>0.9$ & 0.987 & Excellent \\
Parsimony adjustment to the NFI (PNFI) & $>0.5$ & 0.809 & Excellent \\
Parsimony adjustment to the CFI (PCFI) & $>0.5$ & 0.820 & Excellent \\
Root mean square error of approximation (RMSEA) & $<0.05$ & 0.042 & Excellent \\
\hline
\end{tabular}

Table 5 Path coefficient estimate results

\begin{tabular}{llllll}
\hline Path & Estimate & $\begin{array}{l}\text { Standard } \\
\text { error (S.E) }\end{array}$ & $\begin{array}{l}\text { Critical } \\
\text { ratio } \\
\text { (C.R) }\end{array}$ & $\begin{array}{l}\text { P value } \\
\text { Standardized } \\
\text { estimate }\end{array}$ \\
\hline Informational influence $\leftarrow$ perceived expertise & .386 & .060 & 6.422 & $* * *$ & .368 \\
Informational influence $\leftarrow$ perceived similarity & .356 & .059 & 6.052 & $* * *$ & .338 \\
Informational influence $\leftarrow$ perceived familiarity & .248 & .051 & 4.882 & $* * *$ & .230 \\
Normative influence $\leftarrow$ perceived expertise & .266 & .064 & 4.186 & $* * *$ & .254 \\
Normative influence $\leftarrow$ perceived similarity & .357 & .063 & 5.685 & $* * *$ & .340 \\
Normative influence $\leftarrow$ perceived familiarity & .342 & .055 & 6.210 & $* * *$ & .318 \\
Purchase intention $\leftarrow$ informational influence & .232 & .071 & 3.251 & .001 & .237 \\
Purchase intention $\leftarrow$ perceived expertise & .159 & .054 & 2.959 & .003 & .155 \\
Purchase intention $\leftarrow$ perceived similarity & .181 & .052 & 3.486 & $* * *$ & .176 \\
Purchase intention $\leftarrow$ perceived familiarity & .009 & .046 & .198 & .843 & .009 \\
Purchase intention $\leftarrow$ normative influence & .407 & .066 & 6.180 & $* * *$ & .416 \\
\hline
\end{tabular}

*** refers to $P<0.001$, indicating that the estimate was significant at the level of 0.001

model fitting. From Table 4, the CMIN/DF value is less than 3 at 1.952, indicating that the sample data fit well with the model. In addition, the remaining statistics of the model fitting are in the ideal range, meaning that the model fits well generally.

\section{Mediating effect test}

The maximum likelihood method was used to estimate the path coefficients. From Table 5, the path coefficients of perceived expertise and perceived similarity to consumers' purchase intention are significant at the levels of 0.05 and 0.001 , respectively; however, the path coefficients of perceived familiarity to purchase intention are not significant. The path coefficients of perceived familiarity, perceived similarity, and perceived expertise to informational influence and normative influence are significant at the level of 0.001 and the coefficients are positive. Therefore, H1a, H1b, H2a, H2b, H3a and $\mathrm{H} 3 \mathrm{~b}$ are supported. The path coefficient of informational influence and normative influence to purchase intention is significant at the level of 0.001 . The significant pathways are shown in Fig. 3. 


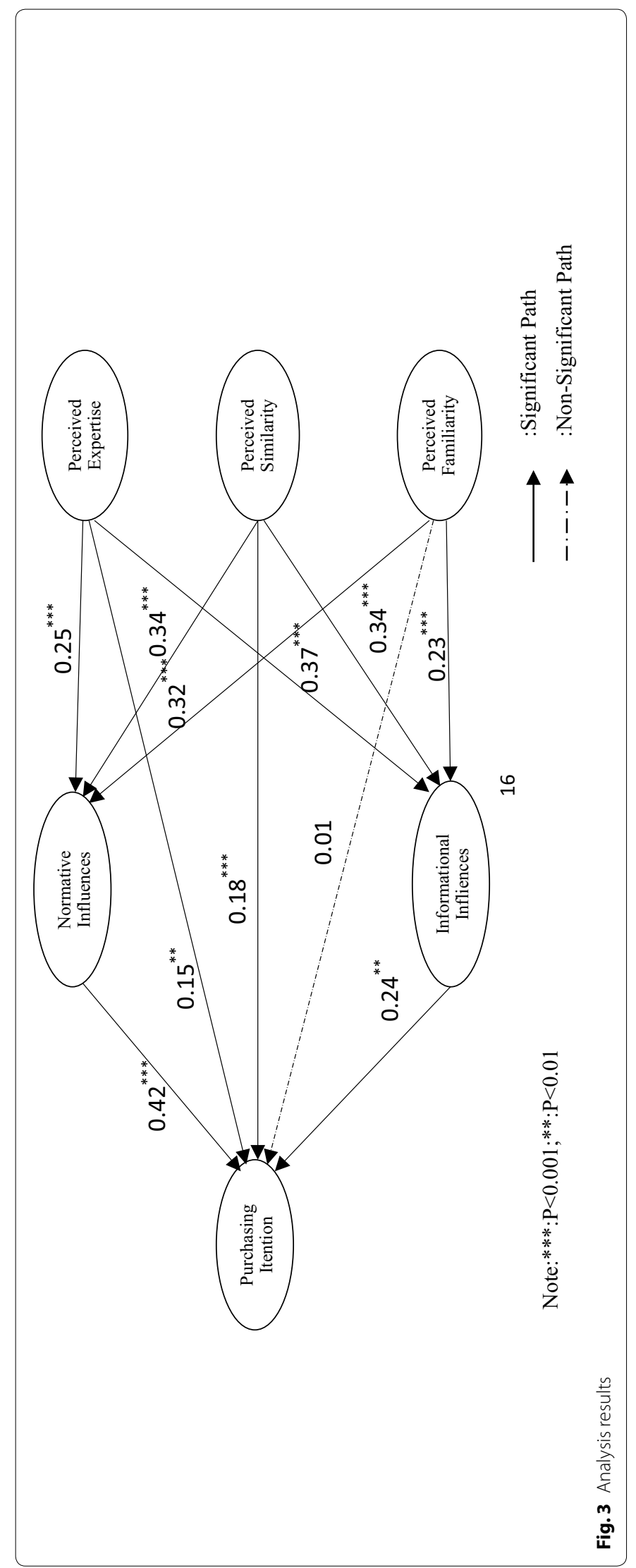


Table 6 Bootstrap-based overall impact test $(n=2000)$

\begin{tabular}{llllll}
\hline Construct & $\begin{array}{l}\text { Perceived } \\
\text { familiarity }\end{array}$ & $\begin{array}{l}\text { Perceived } \\
\text { similarity }\end{array}$ & $\begin{array}{l}\text { Perceived } \\
\text { expertise }\end{array}$ & $\begin{array}{l}\text { Normative } \\
\text { influence }\end{array}$ & $\begin{array}{l}\text { Informational } \\
\text { influence }\end{array}$ \\
\hline $\begin{array}{c}\text { Normative influ- } \\
\text { ence }\end{array}$ & $.318(.001)$ & $.340(.001)$ & $.254(.001)$ & - & - \\
$\begin{array}{c}\text { Informational } \\
\text { influence }\end{array}$ & $.230(.001)$ & $.338(.001)$ & $.368(.001)$ & - & - \\
$\begin{array}{c}\text { Purchase inten- } \\
\text { tion }\end{array}$ & $.195(.002)$ & $.398(.001)$ & $.348(.001)$ & $.416(.002)$ & $.237(.057)$ \\
\hline
\end{tabular}

Table 7 Bootstrap-based direct impact test $(n=2000)$

\begin{tabular}{llll}
\hline Construct & Perceived familiarity & Perceived similarity & Perceived expertise \\
\hline Purchase intention & $.009(.862)$ & $.176(.004)$ & $.155(.029)$ \\
\hline
\end{tabular}

Table 8 Bootstrap-based indirect impact test $(n=2000)$

\begin{tabular}{llll}
\hline Construct & Perceived familiarity & Perceived similarity & Perceived expertise \\
\hline Purchase intention & $.187(0.001)$ & $.222(0.001)$ & $.193(0.001)$ \\
\hline
\end{tabular}

The mediating effect of the model was tested by adopting the bootstrap method $(n=2000)$. The significance test results of the model's overall impact are shown in Table 6. Perceived similarity, perceived familiarity, and perceived expertise have a significant effect on the purchase intention at the level of 0.001 , and the coefficient is positive. Therefore, H6, H7, and $\mathrm{H} 8$ are supported. The effects of both the informational influence and the normative influence on purchase intention are significant at the levels of 0.05 and 0.1 , respectively, and the coefficients are positive. Therefore, $\mathrm{H} 4$ and $\mathrm{H} 5$ are supported.

The significance test results of the model's direct impact are shown in Table 7. The direct impact of perceived similarity and perceived expertise on purchase intention is significant at the level of 0.05 , and the direct impact of perceived familiarity on purchase intention is not significant.

The significance test results of the model's indirect impact are shown in Table 8. The indirect impact of perceived familiarity, perceived similarity, and perceived expertise on purchase intention are significant at the 0.001 level, and the coefficients are all positive; thus, $\mathrm{H} 9$ and $\mathrm{H} 10$ are supported.

The analysis of the model fitting results from Table 6 to Table 8 indicates that the normative and informational influence have a mediating effect on the influence of perceived familiarity on the consumer's purchase intention and a partial mediating effect on the influence of perceived similarity and perceived expertise on the purchase intention. The direct impact of perceived similarity on purchase intention is $44 \%(0.176 / 0.398)$, and the indirect impact is $56 \%(0.222 / 0.398)$; the direct impact of perceived professionalism on purchase willingness is $45 \%(0.155 / 0.348)$, and the indirect impact is $55 \%(0.193 / 0.348)$. 


\section{Conclusions}

Besides providing a new theoretical perspective, this paper analyzes the influence mechanism between online interpersonal interaction and consumers' purchase intention from the perspective of reference groups, which can be viewed as a compensation for the insufficiency in the research of previous scholars.

\section{Theoretical implications}

First, concerning normative influence, several hypotheses are tested. Significant relationships are confirmed between perceived familiarity, similarity and expertise to normative influence. Consumers exposed to interpersonal interaction factors, are more susceptible to the impact of perceived similarity. A possible explanation is that the extent to which individuals perceive similarity with referent others who comprise their social group is a key indicator of their identification with the group [34].

Second, perceived familiarity, similarity and expertise also relate significantly and positively to informational influence. However, perceived expertise contributes the most to the informational influence. In other words, informational influence is often easy to be exerted by persons who are perceived as knowledgeable, credible and having expertise.

Meanwhile, our analysis indicates that the three dimensions of human interaction (perceived familiarity, similarity, and expertise) have different influences on consumers' purchase intention, but they all have significant relationships. Perceived familiarity does not directly strengthen consumers' purchase intention. However, it does influence consumers' decisions based on the normative influence and the informational influence of reference groups.

Third, the normative and informational influences have mediating effects on perceived similarity, expertise and purchase intention. Additionally, the indirect impact of perceived similarity on purchase intention is more than direct impact, so does the perceived expertise. The results imply that perceived similarity and expertise bring the normative and informational influences and further increase the intention to purchase. On the one hand, when consumers perceive that others are similar and professional to them, individuals are likely to experience greater levels of personal identification, which in turn makes them conforming to group norms to have purchase intention [35]. On the other hand, personal interaction with similar and professional peers to exchange information can lead to a perception of trust, which in turn facilitates consumers' purchase intention to buy [36].

\section{Managerial implication}

According to the empirical results and the existing references, this paper primarily explores how companies stimulate consumers' purchase intention by promoting interpersonal consumer interactions on the Internet and strengthening the reference group influence from the perspective of marketing.

First, this study suggests practitioners to pay attention on the construction of online shopping communities. Individuals who have a strong affinity and emotional resonance should be grouped to strengthen interpersonal interactions, which can increase familiarity and similarity among groups. 
Second, practitioners should provide professional shopping guidance in the forms of professional and scientific introductions and articles for marketing. Marketers can build WeChat-based virtual communities and promote communication and learning through the establishment of public WeChat accounts, which will stimulate more consumer behaviors.

Third, the identity and sense of belonging by group members should be strengthened. Consumption can be promoted by exchanging information and group recognition. Marketers can strengthen the after-sales service of goods, satisfy the consumers' after-sales needs, and enhance the recognition of goods or services among group members. Marketers can also encourage consumers to review the products before they purchase, to share experiences and strengthen their sense of belonging to the group, thereby developing informational influence algorithm to promote remote communication [37].

Future research is suggested to apply the proposed SOR model in other marketing settings, and to justify the performance of this study with other methods.

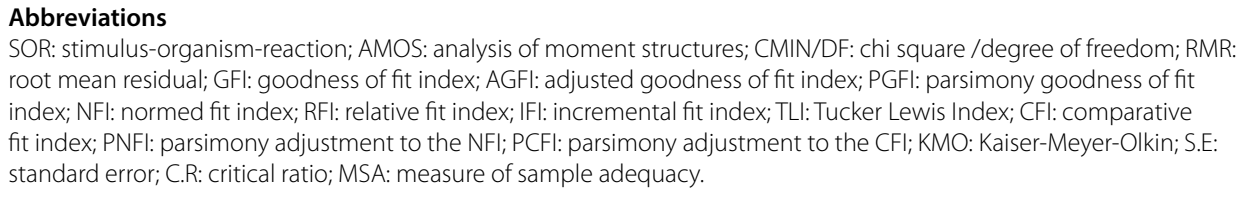

Author details

${ }^{1}$ Business School, Central South University, Changsha, China. ${ }^{2}$ School of Mathematics and Statistics, Hunan Normal University, Changsha, China. ${ }^{3}$ Hunan Provincial Research Institute of Education, Changsha, China.

\section{Acknowledgements}

We would like to thank the reviewers for their valuable comments.

Competing interests

The authors declare that they have no competing interests.

Availability of data and materials

The datasets used during the current study are available from the corresponding author on reasonable request.

Funding

This work was supported by the National Natural Science Foundation of China (No. 71431006).

\section{Publisher's Note}

Springer Nature remains neutral with regard to jurisdictional claims in published maps and institutional affiliations.

Received: 20 August 2018 Accepted: 26 November 2018

Published online: 11 December 2018

\section{References}

1. Walther Joseph B (1992) Interpersonal effects in computer-meditated interaction: a relational perspective. Commun Res 19(1):52

2. Park CW, Lessig VP (1977) Students and housewives: differences in susceptibility to reference group influence. J Consum Res 4(2):102-110

3. Hayes AF, Scharkow M (2013) The relative trustworthiness of inferential tests of the indirect effect in statistical mediation analysis: does method really matter? Psychol Sci 24(10):1918-1927

4. Mehrabian A, Russell JA (1980) An approach to environmental psychology. MIT, Cambridge

5. Park MS, Shin JK, Ju Y (2014) The effect of online social network characteristics on consumer purchasing intention of social deals. Glob Econ Rev 43(1):25-41

6. Liu H, Chu H, Huang Q, Chen X (2016) Enhancing the flow experience of consumers in China through interpersonal interaction in social commerce. Comput Hum Behav 58:306-314

7. Schutz W C (1966) FIRO: a three-dimensional theory of interpersonal behavior. Science \& Behavior Books 148 
8. Wu W, Pirbhulal S, Sangaiah AK, Mukhopadhyay SC, Li G (2018) Optimization of signal quality over comfortability of textile electrodes for ECG monitoring in fog computing based medical applications. Future Gener Comput Syst 86:515-526

9. Bruhn M et al (2014) Antecedents and consequences of the quality of e-customer-to-customer interactions in B2B brand communities. Ind Mark Manage 43(1):164-176

10. Berry LL (2000) Cultivating service brand equity. J Acad Mark Sci 28(1):128-137

11. Van Noort G, Voorveld HAM, Van Reijmersdal EA (2012) Interactivity in brand web sites: cognitive, affective, and behavioral responses explained by consumers' online flow experience. J Interact Mark 26(4):223-234

12. Hyman HH (1942) The psychology of status. Archives of psychology

13. Deutsch M, Gerard HB (1955) A study of normative and informational interaction influences upon individual judgment. J Abnorm Interact Psychol 51(3):629-636

14. Henningsen MLM, Henningsen DD, Cruz MG, Morrill J (2003) Social influence ingroups: a comparative application of relational framing theory and the elaborationlikelihood model of persuasion. Commun Monogr 70(3):175-197

15. Shen YC, Huang $\mathrm{CY}$, Chu CH et al (2010) Virtual community loyalty: an interpersonal-interaction perspective. Int J Electron Commer 15(1):49-74

16. Rockett TL, Okhuysen GA (2002) Familiarity in groups: exploring the relationship between inter-member familiarity and group behavior. Research on Managing Groups and Teams, 4:173-201

17. Janssen J, Erkens G, Kirschner PA et al (2009) Influence of group member familiarity on online collaborative learning[J]. Comput Hum Behav 25(1):161-170

18. Al-Natour S, Benbasat I, Cenfetelli RT (2005). The role of similarity in ecommerce interactions: the case of online shopping assistants. In SIGHCI 2005 proceedings, 4

19. Berscheid E, Snyder M, Omoto AM (1989) Issues in studying close relationships: conceptualizing and measuring closeness. In: Hendrick C (ed) Review of personality and social psychology: close relationships, vol 10. Sage Publications, Inc, Thousand Oaks, pp 63-91

20. Cox DF, Rich SU (1964) Perceived risk and consumer decision-making: the case of telephone shopping. J Mark Res 1(4):32-39

21. Wu W, Zhang H, Pirbhulal S, Mukhopadhyay SC, Zhang YT (2015) Assessment of biofeedback training for emotion management through wearable textile physiological monitoring system. IEEE Sens J 15(12):7087-7095

22. Thornton D, Arrowood AJ (1966) Self-evaluation, self-enhancement, and the locus of social comparison. J Exp Soc Psychol 1:40-48

23. Burnkrant RE, Cousineau A (1975) Informational and normative social influence in buyer behavior. J Consum Res 2:206-215

24. Zhu S, Chen J (2016) E-commerce use in urbanising china: the role of normative social influence. Behav Inf Technol 35(5):357-367

25. Kuan KKY, Zhong Y, Chau PYK (2014) Informational and normative social influence in group-buying: evidence from self-reported and EEG data. J Manag Inf Syst 30(4):151-178

26. Sadler P, Ethier N, Woody E (2011) Interpersonal complementarity

27. Graham KA, Dust SB, Ziegert JC (2018) Supervisor-employee power distance incompatibility, gender similarity, and relationship conflict: a test of interpersonal interaction theory. J Appl Psychol 103(3):334-346

28. Zhang $L$ (2017) The path analysis of online interpersonal interaction on purchase intention based on two-factor structure of trust and distrust. International Conference on Modern Economic Technology and Management

29. Gilly MC, Graham JL, Wolfinbarger MF et al (1998) A dyadic study of interpersonal information search. J Acad Mark Sci 26(2):83-100

30. Voyer Peter A (2000) Word-of-mouth processes within a services purchase decision context. J Serv Res 3(2):166-167

31. Hu X, Huang Q, Zhong X et al (2016) The influence of peer characteristics and technical features of a social shopping website on a consumers purchase intention. Int J Inf Manage 36(6):1218-1230

32. Bearden WO, Netemeyer RG, Teel JE (1989) Measurement of consumer susceptibility to interpersonal influence. J Consum Res 15(4):473-481

33. Bai Y, Yao Z, Dou YF (2015) Effect of social commerce factors on user purchase behavior: an empirical investigation from renren.com. Int J Inf Manage 35(5):538-550

34. Tajfel H, Turner JC (1986) The social identity theory of intergroup behavior. In: Worchel S, Austin WG (eds) Psychology of intergroup relations. Nelson-Hall, Chicago, pp 7-24

35. Rimal RN, Lapinski MK, Cook RJ et al (2005) Moving toward a theory of normative influences: how perceived benefits and similarity moderate the impact of descriptive norms on behaviors. J Health Commun 10(5):433-450

36. Zhang Z, Gu C (2015) Effects of consumer social interaction on trust in online group-buying contexts: an empirical study in China. J Electron Commer Res 16(1):1-21

37. Pirbhulal S, Zhang H, Wu W, Mukhopadhyay SC, Zhang YT (2018) Heart-beats based biometric random binary sequences generation to secure wireless body sensor networks, 2018. IEEE Trans Biomed Eng. https://doi. org/10.1109/TBME.2018.2815155 